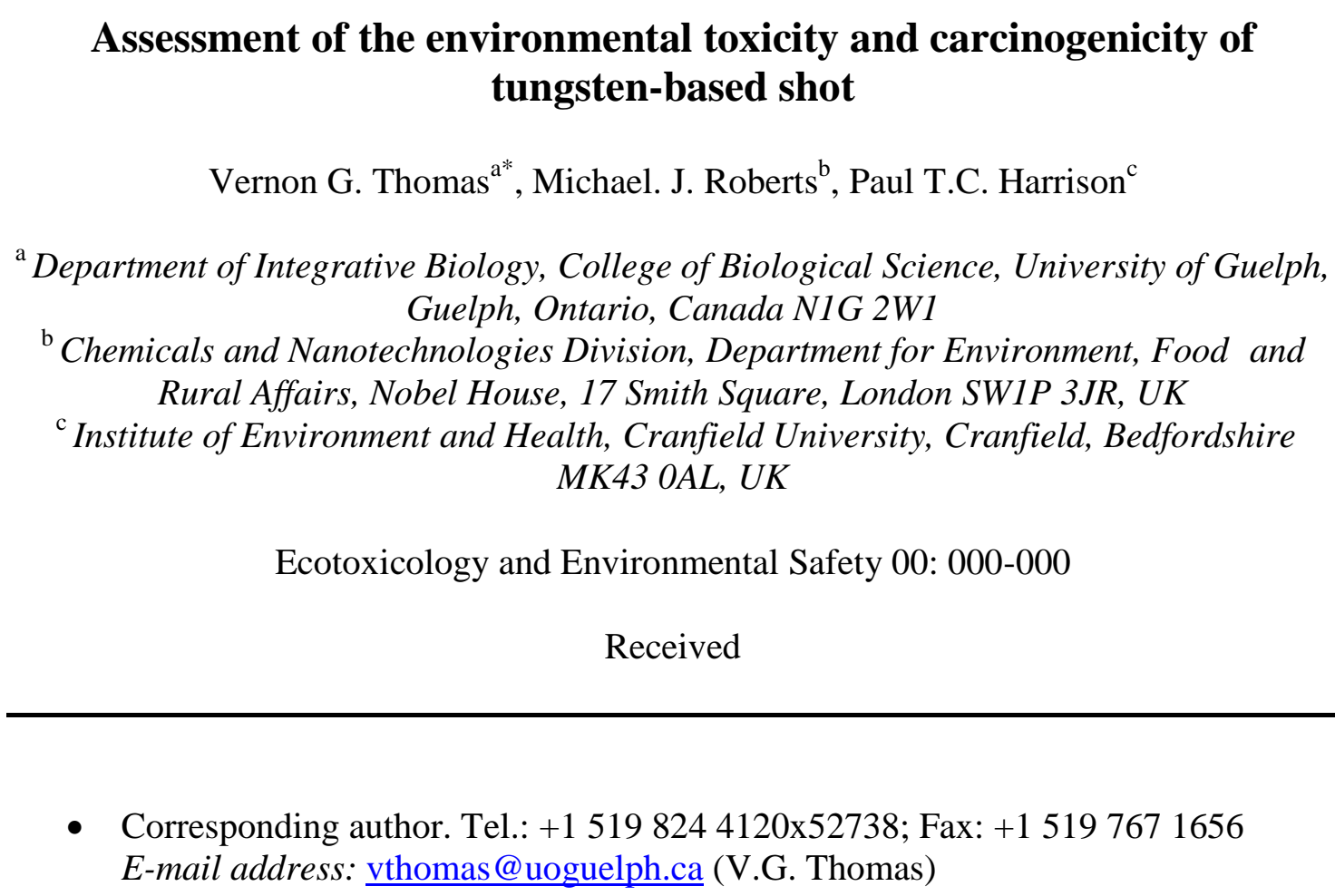

${ }^{a}$ Department of Integrative Biology, College of Biological Science, University of Guelph,

\section{Assessment of the environmental toxicity and carcinogenicity of tungsten-based shot}

- Corresponding author. Tel.: +1 519824 4120x52738; Fax: +1 5197671656 E-mail address: vthomas@uoguelph.ca (V.G. Thomas) 


\begin{tabular}{rl}
1 & Abstract \\
2 & The toxicity of elemental tungsten released from discharged shot was assessed against \\
3 & previous studies that established a $1 \%$ toxic threshold for soil organisms. Extremely \\
4 & heavy theoretical shot loadings of 69,000 shot/ha were used to generate estimated \\
5 & environmental concentrations (EEC) for two brands of tungsten-based shot containing \\
6 & $51 \%$ and $95 \%$ tungsten. The corresponding tungsten EEC values were $6.5-13.5 \mathrm{mgW} / \mathrm{Kg}$ \\
7 & soil, far below the $1 \%$ toxic threshold. The same shot loading in water produced tungsten \\
8 & EEC values of $2.1-4.4$ mgW/L, levels that are not toxic under experimental conditions. \\
9 & Pure tungsten has not been shown to exhibit carcinogenic properties when ingested or \\
10 & embedded in animal tissues, but nickel, with which it is often alloyed, has known \\
11 & carcinogenicity. Given the large number of waterfowl that carry shot embedded in their \\
12 & body, it is advisable to screen lead shot substitutes for their carcinogenic potential \\
13 & through intra-muscular implantation. \\
14 & \\
15 & \\
16 & \\
17 & Keywords: Tungsten; Alloys; Environmental toxicity; Carcinogenicity; Shot \\
\hline
\end{tabular}




\section{Sources of funding}

2

3

4

5

6

7

8

9
This study was funded entirely by the personal private funds of the authors.

\section{Declaration of Protection of Human Subjects and Animal Welfare}

The authors respect this declaration. The content of this paper is not based on results obtained directly by the authors from experimental research on humans or animals. 


\section{1. Introduction}

The large body of evidence implicating spent lead gunshot in the primary lead poisoning of waterfowl and the secondary lead poisoning of birds of prey (USFWS, 1986; Fisher et al., 2006) has lead to a rapid development of lead substitutes, especially since 1991 when the USA and Norway banned the use of lead shot for hunting waterfowl (Beintema, 2001). To date, lead substitutes made from iron, tin, bismuth-tin, tungstenplastics, tungsten-bronze, tungsten-nickel-iron, tungsten-iron and other mixtures of these metals have been developed and approved for legal use in the USA and Canada (USFWS, 2006). The utility of tungsten in these forms of shot relates to its high density $\left(19.35 \mathrm{~g} / \mathrm{cm}^{3}\right)$ and the need to develop substitutes that approach the ballistic characteristics of lead. The Canadian and US legal processes for regulating the composition of new substitutes require that empirical evidence be generated from controlled toxicity tests indicating that shot ingested by waterfowl do not pose a toxic threat to the birds (USFWS, 1997). The need to demonstrate that a new candidate shot is non-toxic to other life forms in the environment is less stringent (Thomas and Guitart, 2003). Nations other than Canada and the USA lack any legal mechanisms to control the composition of lead substitutes (Thomas and Guitart, 2003), whether used as gunshot or fishing weights. The legal approval of tungsten as a non-toxic component of gunshot is based mainly on avian studies conducted over at least 150 days and across two generations under conditions that would demonstrate pathologies and diverse toxic signs, were the material toxic (USFWS, 1997). Recently, based on studies of soil organisms, concerns have been raised about the toxicity of tungsten and certain tungsten alloys to components of the environment other than waterfowl (Begley 2004; Dermatas et al., 2004; Strigul et al., 2005; 
1 Koutsospyros et al., 2006). Ogundipe et al. (2007) used these concerns as a basis for

2 questioning the use of tungsten-based shot. Kalinich et al. (2005) implicated a tungsten

3 alloy in the generation of malignant tumours when implanted intra-muscularly in F344

4 rats. It has also been suggested that tungsten of geological origin might be involved in

5 the cluster of childhood leukemias at Fallon, Nevada (CDC, 2003).

6

7 It has only been during the past decade that release of elemental tungsten to the aquatic

8 and terrestrial environment through game shooting has taken place, and independent,

9 detailed studies of the environmental effects of tungsten are few compared to those of

10 other heavy metals such as cadmium and mercury. The purpose of this paper is to assess

11 the risk posed by spent tungsten shot to organisms other than waterfowl and to investigate

12 whether the putative carcinogenicity of tungsten is due to tungsten per se, or other metals

13 that tungsten may be combined with in shot. Also, by comparing the amount of tungsten

14 that would be released to the environment under the most extremely heavy shooting

15 conditions with levels of tungsten that Strigul et al. (2005) regarded as toxic, we can

16 begin to assess the environmental risk posed by spent tungsten-based shot.

\section{2. Establishing the environmental conditions as the basis for comparison}

21 established a "worst case scenario" for assessing the potential toxicity of a candidate non-

22 toxic (non-lead) shot. In this, it is assumed that 69,000 shot of No. 4 size $(3.07 \mathrm{~mm}$

23 diameter) will be dispersed over 1 hectare of soil to a depth of $5 \mathrm{~cm}$, or over 1 hectare of

24 water to a depth of $30.48 \mathrm{~cm}$. Then, based on the percentage of tungsten (by mass) in the 
1 shot material, the Estimated Environmental Concentration (EEC) of tungsten can be

2 calculated as the amount of tungsten in $500 \mathrm{~m}^{3}$ of soil, or $3048 \mathrm{~m}^{3}$ of water. The EEC

3 value assumes that all of the tungsten in the shot has been solubilized, that adsorption of

4 tungsten onto organic and inorganic fractions in both soil and water has not occurred, and

5 that all of the tungsten is available biologically. The figure of 69,000 shot per hectare is

6 based on known densities of spent shot in the most heavily shot-over regions of the USA.

7 It represents a theoretical shot density meant to challenge the potential non-toxicity of

8 any lead shot substitute. Since this scenario can be applied to shooting situations world-

9 wide, it is the basis of the present comparison.

10

11 Two commercial tungsten-based shot types were used for the comparison. Tungsten-

12 matrix shot comprises $95 \%$ tungsten by mass and tungsten-bronze shot comprises $51 \%$

13 tungsten by mass. Both brands of cartridge are sold widely in North America, and they

14 represent the upper and lower levels of elemental tungsten in the non-toxic shot

15 formulations (Table 1). Given the mass of a single No. 4 tungsten-matrix shot as $213 \mathrm{mg}$,

16 the calculated tungsten EEC for water is $4.44 \mathrm{mg} / \mathrm{L}$ and, for soil, is $13.54 \mathrm{mg} / \mathrm{Kg}$, where

17 soil has a mass of $2 \mathrm{Kg} / \mathrm{L}$. The mass of 1 pellet of tungsten-bronze shot is $183.2 \mathrm{mg}$ : the

18 tungsten EEC for water is $2.12 \mathrm{mg} / \mathrm{L}$ and, for soil, $6.46 \mathrm{mg} / \mathrm{Kg}$.

20 The EEC for tungsten in other brands of tungsten-based shot can be calculated from

21 their gross composition (Table 1). Similarly, the tungsten EEC in soils of density other 22 than 2.0 can readily be calculated, arithmetically. 


\section{3. Comparison of EEC values with other studies reporting tungsten toxicity}

3 Strigul et al. (2005) reported that tungsten powders incorporated into soil at levels

4 exceeding $1 \%$ by mass induced changes in the soil community, such as death of bacteria

5 and an increase in the fungal population. The same study indicated that the degradation of

6 starch applied to soil was inhibited completely when the soil contained more than $3 \%$

7 tungsten by mass. This study also observed the effects of tungsten powders in soils on

8 the survivability of earthworms, concluding that all the worms survived 14 days of

9 exposure to $10-1,000 \mathrm{mg}$ tungsten $/ \mathrm{Kg}$ soil.

10

11 Studying the effects of tungsten on the survivability of soil bacteria, Strigul et al.

12 (2005) reported that, after three months, 95\% of bacteria had died following exposure to

13 soils containing $3 \%$ tungsten by mass. However, when highway soils were treated with

14 tungsten on a $1 \%$ and $0.01 \%$ mass basis, no significant toxic effects were observed at the

$150.01 \%$ concentration (i.e. $100 \mathrm{mg}$ tungsten/Kg soil) after one year. Strigul et al. (2005)

16 also reported that ryegrass germinated in soils containing $10 \%$ by mass tungsten died

17 after one month. A threshold level of soil tungsten was identified as $0.1-1 \%$ by mass for

18 inhibition of ryegrass growth. The authors concluded from these results that elemental

19 tungsten in soils could have detrimental environmental effects above a threshold level of

$201 \%$. In studies on solubility, sorption and soil respiration of tungsten and tungsten alloys,

21 Dermatas et al. (2004) reported that elemental tungsten added to soils above 3\% by mass

22 adversely affected the respiration of soil microbes. 
As previously detailed, the tungsten EEC levels for tungsten-matrix shot and tungstenbronze shot in a 'worst-case' scenario with the heaviest shot loading circumstances are

$313.54 \mathrm{mg} / \mathrm{L}$, and $6.46 \mathrm{mg} / \mathrm{Kg}$ soil, respectively. These two values - equivalent to

$4 \quad 0.0014 \%$ and $0.0006 \%$ respectively - are far below the $1 \%$ and $3 \%$ by mass threshold

5 levels that Strigul et al. (2005) and Dermatas et al. (2004) identified as being toxic to soil

6 communities.

8 Ogundipe et al. (2007) cited a study by Tajima (2003) to demonstrate the potential 9 toxicity of tungsten. However, Tajima (2003) concluded that, based on the influence of

10 soluble tungsten salts on the activity of the umuDc gene in E. coli, tungsten salts were

11 both biologically and toxicologically inert. Tajima indicated that soluble tungsten salts

12 have biological effects on E. coli, but did not equate these to toxicity. Sugio et al. (2001)

13 investigated the mechanism of the inhibition of growth of Acidithiobacillus ferooxidans

14 by sodium tungstate and observed that growth was inhibited in media where the salt

15 concentration was $14.7 \mathrm{mg} / \mathrm{L}$. This level is higher than the 'worst-case' tungsten EEC for

16 both types of shot under consideration.

18 Under circumstances where tungsten becomes solubilized, there is a potential for 19 tungsten salts to become adsorbed onto organic and mineral components of both soil and

20 water. Dermatas et al. (2004) reported that soil fractions readily adsorb tungstate salts in a

21 non-reversible manner. Presumably, this would lower the soil EEC values for tungsten,

22 depending on the degree of adsorption and affirm further the non-toxicity of spent

23 tungsten-based shot to soil organisms. 
1 It is informative to relate the 'worst-case' scenario tungsten EEC values to naturally-

2 occurring levels of tungsten in the environment. Senesi et al. (1988) measured the level of

3 naturally-occurring tungsten in an array of soils and reported background levels between

$4 \quad 0.2-2.4 \mathrm{mg} / \mathrm{L}$ soil. Extrapolating from these levels, the heaviest tungsten soil loading from

5 spent shot at the most heavily shot-over sites would be, at most, five times the highest

6 background level. Quin and Brooks (1972a) measured tungsten in the soils around

7 agricultural lands in New Zealand, reporting levels of 1.9-21.4 mgW/Kg soil. However,

8 in areas where the soils were heavily-mineralized, tungsten levels were much higher,

9 ranging from 65-125 $\mathrm{mgW} / \mathrm{Kg}$ (Quin and Brooks, 1972b). The 'worst-case' tungsten

10 EECs for both brands of tungsten shot fall far below these levels. The federal

11 governments of Canada and the U. S. Environmental Protection Agency do not have

12 standards for tungsten in sludges or biosolids applied to soils (see USEPA, 1995).

\section{4. Potential toxicity of soluble tungsten in drinking water}

The USA, Canada and the Member States of the European Union do not have potable

17 water standards for tungsten. A number of independent studies have investigated the

18 effects of ingested soluble forms of tungsten in drinking water on different physiological

19 parameters. Rats given sodium tungstate at $200 \mathrm{mg} / \mathrm{L}$ for 20 weeks did not exhibit

20 changes in body weight or any notable histopathology (Luo et al., 1983). Giving rats

21 drinking water containing $100 \mathrm{mg}$ sodium tungstate/L for three weeks produced no

22 effects on bodyweight or liver weight, nor effects on succinate-cytochrome c reductase ${ }^{1}$

23 activity (Cohen et al., 1973). Munoz et al. (2001) reported no deleterious effects on

\footnotetext{
${ }^{1}$ A mitochondrial respiratory enzyme.
} 
1 growth or on the liver and kidney of rats given drinking water containing $2000 \mathrm{mg}$

2 sodium tungstate /L for two months. Schroeder and Mitchener (1975) reported that rats

3 given tungsten at $5 \mathrm{mg} / \mathrm{L}$ in their drinking water for their entire life showed a slight

4 increase in growth and a slight reduction in longevity.

6 Given that the 'worst-case' aquatic tungsten EEC for tungsten-matrix shot and

7 tungsten-bronze shot are $4.44 \mathrm{mg} \mathrm{W} / \mathrm{L}$ and $2.12 \mathrm{mgW} / \mathrm{L}$ respectively, the above-cited

8 studies on the effects on rats of drinking water containing much higher levels of sodium

9 tungstate indicate that concerns relating to the possible toxicity of animals' drinking

10 water containing soluble tungsten derived from spent shot are unwarranted.

\section{5 . Implicating tungsten in carcinogenicity}

14 While this review deals primarily with the fate of elemental tungsten in gunshot,

15 tungsten compounds of geological origin and other anthropogenic origins can enter the

16 human environment and the human food chain through potable water and other ingesta.

17 Concerns about a potential carcinogenic role of tungsten have arisen from tungsten

18 compounds in drinking water (CDC, 2003) and the use of tungsten in ballistic heavy

19 metal alloys (Kalnich et al., 2005) and have been used to question the presence of

20 tungsten in new types of gunshot.

21

22 5.1. Carcinogenicity associated with tungsten in potable water 
The deposition of gunshot in water bodies and wetlands by intense hunting pressure across years raises the possibility that tungsten could become mobilized from the shot and become part of human potable water. In situations where such gunshot undergoes

4 slow disintegration on dry land, small particles of tungsten, either as metal or tungsten

5 compounds, could reach humans and be inhaled or ingested. Kalinich (2005),

6 Koutsospyros et al. (2006), and Ogundipe et al. (2007) referred to a possible relationship

7 between tungsten in the environment of humans in Fallon, Nevada, USA and certain

8 types of leukemia in children. This occurrence of leukemia in children has been examined

9 in detail as to its possible cause(s), including (but not confined to) the presence of

10 elevated levels of soluble tungsten in the potable groundwater. Seiler et al. (2005)

11 identified elevated levels of tungsten in ground water around Carson Desert, Nevada, and

12 attributed these levels to the natural erosion of tungsten bearing minerals in the local

13 watershed, possibly reinforced by upwelling from deep warm waters. Sheppard et al.

14 (2006) measured both tungsten and cobalt levels in atmospheric particles from the Fallon,

15 Nevada region, and suggested that they originated from a hard-metal processing plant in

16 Nevada. Whatever the origin (natural and/or anthropogenic) and form of the tungsten in

17 the human environment, mention and examination of its potential carcinogenicity is

18 warranted.

20 The Centers for Disease Control and Prevention concluded that while tungsten was " $a$ 21 potentially unique exposure within Churchill County" [i.e. Fallon], it was not identified 22 as the cause of the leukemia (CDC, 2003) and this Agency could not detect a statistically 23 significant relationship between exposure to ingested tungsten in drinking water and 
1 childhood leukemia in Churchill County, Nevada (CDC, 2003). The Expert Panel on

2 Childhood Leukemia in Churchill County, Nevada (Expert Panel on Childhood

3 Leukemia, 2004) concluded that tungsten had likely been present in that environment for

4 many years (from mining, a tungsten smelter and use of tungsten ammunition at a nearby

5 military base) and could not link tungsten in the human environment to leukemia in

6 children. Furthermore, three major agencies, the U.S. Department of Health and Human

7 Services, the U.S. Environmental Protection Agency and the International Agency for

8 research on Cancer, have not linked tungsten exposure with carcinogenic effects.

9 However, the U.S. National Toxicology Program has been advised to investigate further

10 all the potential effects of tungsten on animal health (ATSDR, 2005a, 2005b).

12 Daughton (2005) suggested that the actual cause(s) of the leukemia remained to be

13 identified and hypothesized that a range of other environmental agents could contribute to

14 carcinogenicity. Rubin et al. (2007) re-evaluated the potential environmental causes of

15 the childhood leukemia in Churchill County, paying special attention to tungsten

16 exposure. These authors could not establish, scientifically, any link between tungsten and

17 leukemia and indicated that the elevated tungsten levels in Churchill County were not

18 unique compared to adjacent regions in which exceptional incidences of leukemia did not

19 occur. However, a recent study by Sheppard et al. (2007) used dendrochemistry to

20 monitor airborne metals in the environment around Fallon, Nevada. Cottonwood

21 (Populus sp.) trees revealed an increase in tungsten levels from the mid-1990s, and

22 increased cobalt levels from an earlier time, but no temporal increases were seen in other

23 metals. The authors recommended that the potential roles of tungsten and cobalt, in 
1 combination, in the generation of tumours be investigated further, a recommendation

2 made also by Sheppard et al. (2006).

4 5.2. Carcinogenicity associated with ingested and muscle-embedded tungsten-based shot

6 Tungsten-based shot can enter the body of animals and humans in several ways. They

7 can be ingested directly as spent shot; they can enter the digestive tract when the tissues

8 of animals killed with tungsten-based ammunition are eaten, as in the case of predators

9 and humans, and the shot may enter the body from non-lethal gunfire and be carried in

10 tissues. The presence of shot in the body can have various toxicological consequences,

11 including acute toxicity, chronic inflammation and carcinogenicity, with different

12 physiological circumstances determining the residency, solubility, excretion and potential

13 toxicity of shot materials in the gut versus shot embedded in muscle ${ }^{2}$.

14

15 It is necessary to consider the variety of metals that may be combined with tungsten in

16 different brands of commercial shot and the manner in which they are combined, since

17 this may determine their bio-availability. Thus tungsten-bronze shot is a sintered mixture

18 of bronze powder and tungsten powder (Thomas et al., 2007), whereas tungsten-nickel-

19 iron shot is a true alloy of these three metals. The physico-chemical interactions among

20 metals in true alloys or sintered mixtures determines how quickly individual metals can

21 be solubilized and exert their influence (Ogundipe et al., 2006).

22

\footnotetext{
${ }^{2}$ Note: Although testing of the (non)toxicity of some new types of shot by implanting them into the muscles of ducks has been conducted, it is not a legal requirement of the US or Canadian regulations.
} 
Ringelman et al. (1993), Kelly et al. (1998), Mitchell et al. (2001a; 2001b; 2001c) and

2 Brewer et al. (2003) have shown that elemental tungsten, whether combined with plastics

3 or sintered or alloyed with other metals, does not pose a toxic threat to captive waterfowl

4 when ingested. It is upon these controlled studies that full, unconditional, approval of

5 tungsten-based shot has been given by the USA and Canada ${ }^{3}$. These studies required

6 histopathological examination of the principal organs of mallard ducks to be examined by

7 certified pathologists. Should any tumours have developed within the 30 or 150 day

8 period, legal approval would not have been given. In a separate study, tungsten-bismuth-

9 tin shot, when embedded in muscles of mallard ducks for eight weeks, did not produce

10 any adverse or toxic effects (Kraabel et al., 1996). To date, only the study by Kraabel et

11 al. (1996) has investigated the effect of embedding tungsten-based shot intra-muscularly

12 in the birds: all the other studies were performed with tungsten-based shot present in the

13 digestive system.

14

15 In the study by Kalinich et al. (2005), tungsten-nickel-cobalt alloy pellets (W 91.1\%:

16 Ni 6.0\%: Co 2.9\%) implanted into the muscle of F344 rats induced potentially fatal

17 malignant tumours, indicating that tungsten alloys are carcinogenic by this exposure

18 route, a point raised also by Koutsospyros et al. (2006). Similar pellets made from nickel

19 also produced tumours, but a tantalum control did not. Unfortunately, the Kalinich et al.

20 (2005) study did not contain a pure tungsten control and so it is not possible to determine

21 the role, if any, played by tungsten itself in the generation of the tumours. The same

22 caveat was noted by ATSDR (2005a). Kalinich et al. (2005) did suggest a possible

\footnotetext{
${ }^{3}$ Approval can be revoked should toxicity issues or other environmental problems arise during use of the new shot.
} 
1 combined effect of all three metals and specifically alluded to possible evidence for

2 synergism between nickel and cobalt.

4 Several independent studies have investigated the long-term effects of pure tungsten

5 coil implants, focusing on in vivo corrosion of the metal and any associated toxicity.

6 Peuster et al. (2003a, 2003b) implanted tungsten coil sutures in rabbit and human tissues

7 and examined their fate and possible toxicity. Peuster et al. (2003a ) concluded that while

8 there was mobilization of tungsten from the suture coils implanted into humans, the rate

9 of mobilization was very low $(29 \mu \mathrm{g} /$ day $)$. The results indicated no toxic effects in human

10 adult and pediatric patients despite elevated serum tungsten levels. In their $2003 \mathrm{~b}$ study,

11 Peuster et al. implanted tungsten coils into the subclavian artery of rabbits and observed

12 the effects four months later. The authors reported an increase in serum tungsten levels

13 from $0.48 \mu \mathrm{g} / \mathrm{L}$ before implantation to $12.4 \mu \mathrm{g} / \mathrm{L}$ four months after implantation. However,

14 the dissolution of tungsten from the coils was not accompanied by any local or systemic

15 toxicity. Corrosion of pure tungsten implants in humans and accompanying elevated

16 blood tungsten levels has also been reported by Butler et al. (2000) and Barrett et al.

17 (2000). However, both studies did not report toxic effects in patients many months after

18 implantation. This line of research was continued by Bachthaler et al. (2004) in which

19 pure tungsten implants were monitored in human patients over several years. These

20 authors did not observe toxic effects in any patient with elevated blood tungsten levels.

21 However, Bachthaler et al. (2004) did caution against the use of such implants because

22 superior materials were available that did not undergo corrosion, and because the clinical

23 significance (if any) of elevated tissue tungsten levels remained to be determined. 
2 Thus there is no direct evidence that pure, elemental tungsten causes toxicity or

3 carcinogenicity. Leggett (1997) developed a model to infer more about the distribution

4 and retention of tungsten in the human body and stated that while the data on this subject

5 are... "weak and inconclusive, the occupational experiences and the available

6 toxicological studies on laboratory animals suggest that tungsten may have a relatively

7 low order of chemical toxicity. van der Voet et al. (2007) did not identify any specific

8 adverse effects attributable to tungsten in a review of this metal's clinical properties.

9 However, these authors stated, explicitly, the need to distinguish between elemental

10 tungsten and other heavy metals with which it is normally alloyed in inducing tumours,

11 and cited nickel and cobalt, specifically, as contributors to such risk. van der Voet et al.

12 (2007) reiterated the precautionary remarks of Butler et al. (2000) and Bachthaler et al.

13 (2004) about elevated levels of tungsten in human tissues and the need for more research,

14 both on the toxic risks posed by the pure metal in the body, and the carcinogenic risks

15 posed by other metals' presence in tungsten alloys.

17 5.2.1 Nickel in tungsten alloys: inflammation and carcinogenicity

19 Hoots et al. (2007) implanted shot made from nickel-coated steel, tungsten-polymer,

20 tungsten-iron and tungsten-nickel iron into the musculature of rats and observed the local

21 and systemic effects 26 weeks later. They found that the three tungsten-based shot types

22 produced no neoplasms after 26 weeks. Nickel-coated steel shot underwent a

23 significantly greater corrosion than the other shot types and produced a marked local 
1 tissue inflammation three weeks after implantation, but not after 26 weeks. Severe

2 inflammatory reactions in rabbit muscle to implants of nickel-cobalt alloys were also

3 reported by Laing et al. (1967) and in rat muscle from implants of pure nickel and cobalt

4 by McNamara and Williams (1981). Uo et al. (2001) reported that nickel implants in rat

5 muscles caused marked tissue damage at the sites of implantation and demonstrated that

6 nickel had the highest relative metal toxicity of all the metals tested. Thus there is strong

7 evidence for the inflammatory effects of implanted nickel, but not pure tungsten.

9 Several independent reviews have established nickel and nickel compounds as

10 carcinogenic. The National Toxicology Program (2005) found a number of studies that

11 revealed the carcinogenic nature of nickel compounds, related to the slow release of

12 nickel ions that exert a genotoxic effect throughout the body. The review of Kasprzak et

13 al. (2003) cites evidence for the genotoxic and mutagenic activity of nickel ions,

14 especially at higher tissue levels. Salnikov and Kasprzak (2005) indicated that a major

15 prerequisite for nickel toxicity is prolonged action at the tissue site, as might occur from

16 the implantation of metallic nickel into muscle.

18 Miller et al. (2000) showed that metallic nickel causes neoplastic transformation in

19 cultured cells. Miller et al. $(2001 ; 2004)$ subsequently attempted to differentiate the

20 potential toxic effects of elemental tungsten, nickel and cobalt that are the principal

21 component of military penetrators. In the 2001 in vitro study on human osteoblast cells,

22 Miller et al. measured a decrease in cell survival after five weeks exposure to tungsten,

23 nickel and cobalt powders in a dose-dependent manner. However the neoplastic 
1 transformation of osteoblasts was far greater when cells were exposed to the tungsten

2 alloys. In a further experiment, Miller et al. (2004) observed dose-dependent activation of

313 gene promoters by tungsten, nickel, and cobalt, alone, but the effect was statistically

4 significant only at the highest dose levels. The genes induced are related to DNA damage

5 and the development of malignancy (Miller et al., 2004). As with the Miller et al. (2001)

6 study, the level of gene induction by each metal was far lower than in the tungsten-

7 nickel-cobalt alloy, indicating an apparent toxic synergy among the three metals. These

8 results, added to those from the study of Kalinich et al. (2005) in which embedded nickel

9 (and nickel-containing) pellets produced malignant tumours in rats, indicate that

10 elemental nickel, whether alone or present in alloyed form with cobalt and tungsten, is

11 carcinogenic.

12

\section{6. Discussion of pertinent findings}

14

15 The assertion made by Ogundipe et al. (2007), that tungsten in the environment from

16 discharged shot is toxic, has not been substantiated using the criteria of Strigul et al.

17 (2005) and Dermatas et al. (2004). Even where very heavy gunshot loadings from spent

18 lead shot may be expected and maximum dissolution and bioavailability of tungsten in

19 the shot is assumed, the predicted amounts of tungsten in the soil fall far below the $1 \%$

20 threshold identified as toxic to soil organisms. This conclusion, based on extremely heavy

21 shot loadings by shooters, applies to commercial brands of tungsten-based shot

22 containing $51-95 \%$ tungsten by mass. 
The manner of soil deposition of metallic tungsten from shot and lead-free bullets made from tungsten may have an important bearing on claims of a toxic tungsten legacy.

3 The studies of Dermatas et al. (2004) and Strigul et al. (2005) were prompted by high

4 tungsten levels in the soils at military rifle training ranges, not areas where gunshot from

5 hunting had fallen. Large numbers of soldiers fire many bullets during training, especially

6 during rapid-fire situations. The bullets are stopped in earthen backstops and, should

7 tungsten remnants accumulate, they could readily exceed the $1 \%$ and $3 \%$ thresholds

8 identified. Remediation of such training sites, involving the reclamation and recycling of

9 tungsten fragments, is possible because they are both readily-accessible and restricted

10 geographically. By contrast, hunting with shotguns occurs across a far wider geographic

11 area, whether over upland or wetland sites, and so there is a greater dispersion of the non-

12 toxic shot that leads to a far slower rate of metal accumulation at a given location.

14 The case for soluble tungsten, alone, in potable water causing childhood leukemia (as

15 in the Churchill County situation) has not been substantiated, despite considerable

16 scientific examination of this issue (Rubin et al., 2007). Dosing rats' drinking water with

17 soluble tungsten salts under experimental conditions with amounts of tungsten far above

18 the 'worst-case' aquatic EEC from shot has not led to tumour development.

20 The experimental testing in ducks of ingested tungsten-based (tungsten-iron and

21 tungsten-polymer) shot under the Tier 3 (150 days exposure across two generations)

22 protocol (USFWS, 1997), by Mitchell et al. (2001a; 2001b; 2001c), did not report

23 carcinogenicity, despite the solubilization of tungsten and its absorption into the 
1 circulation. Tungsten-plastic shot is made from pure tungsten powder mixed with an inert

2 plastic and so relates most closely to the experimental testing of pure tungsten (as

3 opposed to shot types made from tungsten alloys). The results of testing ingested

4 tungsten-plastic shot in ducks are consistent with the results of Barrett et al. (2000),

5 Butler et al. (2000), Peuster et al. (2003a; 2003b) and Bachthaler et al. (2004), in which

6 pure tungsten coils were observed not to cause toxicity in both humans and rabbits. In

7 view of these results, it is suggested that tungsten-plastic shot and other tungsten-based

8 shot taken into the gut of scavenging birds and mammals, and humans who eat shot in the

9 tissues of game, will not cause adverse local or systemic effects.

11 In North America and Europe, many birds are wounded each year from non-lethal

12 gunfire from waterfowl hunters. The percentage of adult birds carrying shot in the body is

13 given as $29.1 \%$ and $20 \%$ for two Eider species (Somateria) in Greenland (Falk et al.,

14 2006). Hicklin and Barrow (2004) found that $25 \%$ of 1624 radiographed waterfowl of

15 different species in Canada contained embedded shot. Tavecchia et al. (2001) reported

16 that up to $29 \%$ of Mallard ducks (Anas platyrhynchos) captured in a given year in the

17 Camargue of France may contain shot embedded in the muscles. The incidence of

18 embedded shot in adult teal (Anas crecca) captured in the same locality was $7.5 \%$ for

19 females and $9.6 \%$ for males (Guillemain et al., 2007). The prevalence of embedded shot

20 appears to be greater for larger-bodied, and longer-lived, geese than ducks. Pink-footed

21 geese (Anser brachyrhynchus) are hunted in Norway and Denmark and, prior to 1997,

$2225 \%$ of juvenile geese and $36 \%$ of older birds contained embedded shot in their muscles

23 (Noer et al., 2007). Forty-four percent of 45 trapped Greylag Geese (Anser anser) 
examined by Mateo et al. (2007) in Spain carried embedded shot. Given that so many millions of waterfowl may live for years with lead shot in their body, it is important to determine if the substitutes for lead shot may have a detrimental impact on the birds'

4 existence beyond the initial wounding. From a management perspective, little gain in

5 waterfowl survival is achieved if toxic lead shot is replaced by materials that, while non-

6 toxic when ingested, pose risks of carcinogenicity when embedded.

8 Some of the new brands of tungsten-based shot approved by the US government are

9 allowed to contain up to $40 \%$ by mass of nickel alloyed with tungsten (USFWS, 2006)

10 (Table 1). As suggested by Salnikow and Kasprzak (2005), a high-nickel-content shot,

11 slowly releasing ions from the site of shot implantation over months to years, might

12 create the conditions for genotoxicity and, indeed, the study of Kalinich et al. (2005) has

13 already demonstrated the carcinogenic potency of both metallic nickel and a $6 \%$ nickel-

14 tungsten alloy implanted in rat muscle.

16 It is suggested that protocols for assessing the potential toxicity of lead shot

17 substitutes, such as that of the USFWS (1997), be amended to include provisions for the

18 testing of candidate shot by intramuscular implantation to determine if prolonged

19 inflammation or tumour development occurs. Kraabel et al. (1996) investigated the

20 effects of embedding tungsten-bismuth-tin shot into the pectoral muscles of ducks after

21 eight weeks (our italics), while Kalinich et al. (2005) showed that the imminent mortality

22 of rats from tumour development attributed to nickel occurred between weeks 23 and 30

23 (our italics) post-implantation. Moreover, the duration of regulatory testing for chemical 
1 carcinogenicity is typically $18-24$ months (our italics). Notwithstanding the likely

2 differences in response between birds and mammals, eight weeks may not be long

3 enough to detect possible long-term inflammation and/or carcinogenic effects of metal

4 implantation in birds. Certainly thirty-day testing, as required under Tier 2 conditions of

5 the USFWS (1997) protocol, will not allow sufficient time; thus the testing of embedded

6 shot should be made part of Tier 3 conditions and the duration of embedding be made

7 commensurate with the time required to demonstrate non-carcinogenicity of the shot

8 materials.

9

10 7. Conclusions

12 The use of tungsten in lead-free shot is not associated with environmental toxicity,

13 even when such shot are present in soil and water at levels exceeding the heaviest known

14 shot burdens. The EEC tungsten levels for two brands of commercial shot containing

$1551 \%$ and $96 \%$ tungsten fall far below the $1 \%$ tungsten threshold that is associated with

16 impacts on soil biota. Extensive medical investigation has not been able to implicate

17 tungsten in potable water as the cause of human leukemia in Nevada, USA. Tungsten is

18 often alloyed with nickel and cobalt, especially for use in military penetrators. Several

19 independent chronic exposure studies have shown that elemental tungsten, whether

20 ingested or implanted in muscle, does not produce tumours or any other pathological

21 condition; however, the nickel present in such alloys is demonstrably carcinogenic when

22 implanted into muscle. Many millions of waterfowl in Europe and North America carry

23 embedded shot in their body as a consequence of non-fatal shooting. The U.S. Fish and 
1 Wildlife Service recently approved several types of shot that may contain up to $40 \%$ nickel. It is appropriate for regulatory agencies to consider the inclusion of an embedded shot (intramuscular implantation) treatment as a new component of the legal

4 requirements when evaluating new 'non-toxic' shot candidates.

Acknowledgements

The scientific views expressed in this paper are those of the authors and may not reflect

8 those of their institutions. We are grateful to the anonymous reviewers for their useful

9 contributions to this paper.

\section{References}

ATSDR (Agency for Toxic Substances and Disease Registry). 2005a. Toxicological profile for tungsten. U.S. Dept. Health and Human Services. Public Health Service. Atlanta, GA.

ATSDR. 2005b. ToxFAQs. Tungsten. CAS\# 7440-33-7. U.S. Dept. Health and Human Services. Public Health Service. Atlanta, GA.

Bachthaler, M., Lenhart, M., Paetzel, C., Feuerbach, S., Link, J., Manke, C. 2004. Corrosion of tungsten coils after peripheral vascular embolization therapy: influence on outcome and tungsten load. Catheter. Cardiovasc. Interv. 62: 380384.

Barrett, J., Wells, I., Riordan, R., Roobottom, C. 2000. Endovascular embolization of varicoceles: resorption of tungsten coils in the spermatic vein. Cardiovasc. Interv. Radiol. 23: 457-459.

Begley, M.J. 2004.Environental impact of new materials: the tungsten bullet experience. In, Sport shooting and the environment: sustainable use of lead ammunition. Proc. World Sympos. Lead Ammunition. World Forum on the Future of Shooting Sport Activities. Rome, Italy, pp. 233-236.

Beintema, N., 2001. Third international update report on lead poisoning in waterbirds. Wetlands International, Wageningen, The Netherlands. 
Butler, T.J., Jackson, R.W., Robson, J.Y., Owen, R.J.T., Delves, H.T., Sieniawska, C.E., Rose, J.D.G. 2000. In vivo degradation of tungsten embolisation coils. Brit. J. Radiol. 73: 601-603.

Brewer, L., Fairbrother, A., Clark, J., Amick, D. 2003. Acute toxicity of lead, steel, and an iron-tungsten-nickel shot to mallard ducks (Anas platyrhynchos). J. Wildl. Diseases 39:638-648.

Centres for Disease Control (CDC). 2003. A cross-sectional exposure assessment of environmental contaminants in Churchill County, Nevada. Final Report. Centres for Disease Control and Prevention. Atlanta, GA. http://www.cdc.gov/nceh/clusters/Fallon/study.htm

Cohen, H.R., Drew, R.T., Johnson, J.L., and Rajagopalan, K.V. 1973. Molecular basis of the biological function of molybdenum. The relationship between sulfite oxidase and the acute toxicity of bisulfite and $\mathrm{SO}_{2}$. Proc. Nat. Acad. Sci 70: 3655-3659.

Daughton, C.G. 2005. Overlooked in Fallon? Environmental Health Perspectives 113: A224-225.

Dermatas, D., Braida, W., Christodoulatos, C., Strigul, N., Panikov, N., Los, M., and Larson, S. 2004. Solubility, sorption, and soil respiration effects of tungsten and tungsten alloys. Environ. Forensics 5: 5-13.

Expert Panel on Childhood Leukemia. 2004. Final Report and Recommendations to Nevada State Health Division. Nevada State Health Division, Carson City, Nevada.

Falk, K., Merkel, F., Kampp, K, Jamieson, S.E. 2006. Embedded lead shot and infliction rates in common eiders Somateria mollissima and king eiders $S$. spectabilis wintering in southwest Greenland. Wildl. Biol. 12: 257-265.

Fisher, I.J., Pain, D.J., Thomas, V.G. 2006. A review of lead poisoning from ammunition sources in terrestrial birds. Biol. Conserv. 131: 421-432.

Guillemain, M., Devineau, O., Lebreton, J.-L., Mondain-Monval, J.-Y., Johnson, A.R., Simon, G. 2007. Lead shot and teal (Anas crecca) in the Camargue, Southern France: effects of embedded and ingested pellets on survival. Biol. Conserv. 137: 567-576.

Hicklin, P.W., Barrow, W.R. 2004. The incidence of embedded shot in waterfowl in Atlantic Canada and Hudson Strait. Waterbirds 27: 41-47.

Hoots, E.A., Renberg, W.C., Patton, K.M., Roush, J.K. 2007. Evaluation of local and systemic effects after intramuscular implantation of lead shot alternatives in rats. Am. J. Vet. Res. 68:446-452. 
Kalinich, J.F. 2005. Tungsten alloy and cancer in rats: Kalinich responds. Environ. Health Perspectives 113: A802.

Kalinich, J.F., Emond, C.A., Dalton, T.M., Mog, S.R., Coleman, G.D., Kordell, J.E., Miller, A.C., McClain, D.E. 2005. Embedded weapons-grade tungsten alloy shrapnel induces metastatic high-grade rhabdomyosarcomas in F344 rats. Environ. Health Perspectives 113: 729-734.

Kasprzak, K., Sunderman, F.W., Salnikow, K. 2003. Nickel carcinogenesis. Mutation Res. 533: 67-97.

Kelly, M.E., Fitzgerald, S.D., Auerlich, R.J., Balander, R.J., Powell, D.C., Stickle, R.L., Stevens, W., Gray, C., Tempelman, R.J., Bursian, S.J. 1998. Acute effects of lead, steel, tungsten-iron, and tungsten-polymer shot administered to game-farm mallards. J. Wildl. Diseases 34: 673-687.

Koutsospyros, A., Braida, W., Christodoulatos, C., Dermatas, D., and Strigul, N. 2006. A review of tungsten: from environmental obscurity to scrutiny. J. Hazardous Materials 136: 1-19.

Kraabel, B.J., Miller, M.W., Getzy, D.M., Ringleman, J.K. 1996. Effects of embedded tungsten-bismuth-tin shot and steel shot on mallards (Anas platyrhynchos). J. Wildl. Diseases 32: 1-8.

Laing, P.C., Ferguson, A.B., Hodge, E.S. 1967. Tissue reaction in rabbit muscle exposed to metallic implants. J. Biomed. Mater. Res. 1: 135-149.

Leggett, R.W. 1997. A model of the distribution and retention of tungsten in the human body. Science of the Total Environment 206: 147-165.

Luo, X.M., Wei, H.J., and Yang, S.P. 1983. Inhibitory effects of molybdenum on esophageal and forestomach carcinogenesis in rats. J. Nat. Cancer Inst. 71: 75-80.

Mateo, R., Green, A.J., Lefranc, H., Baos, R., Figuerola, J. 2007. Lead poisoning in wild birds from southern Spain: A comparative study of wetland areas and species affected, and trends over time. Ecotox. Environment. Safety 66: 119-126.

McNamara, A., Williams, D.F. 1981. The response to the intramuscular implantation of pure metals. Biomaterials 2: 33-40.

Miller, A.C., Brooks, K., Smith, J., Page, N. 2004. Effect of the military-relevant heavy metals, depleted uranium and heavy metal tungsten-alloy on gene expression in human liver carcinoma cells (HepG2). Molec. Cell. Biochem. 255: 247-256. 
Miller, A.C., Mog, S., McKinney, L. Luo,L., Allen, J., Xu, J., Page, N. 2001. Neoplastic transformation of human osteoblast cells to the tumorigenic phenotype by heavy metal-tungsten alloy particles: induction of genotoxic effects. Carcinogenesis 22: 115-125.

Miller, A.C, Xu, J., Stewart, M., Emond, C., Hodge, S., Mathews, C.R., Kalinich, J., McClain, D. 2000. Potential health effects of the heavy metals, depleted uranium and tungsten, used in armor-piercing munitions: Comparison of neoplastic transformation, mutagenicity, genomic instability, and oncogenesis. Metal Ions in Biol. Med. 6: 209-211.

Mitchell, R.R., Fitzgerald, S.D., Auerlich, R.J., Balander, R.J., Powell, D.C., Templeman, R.J., et al. 2001a. Health effects following chronic dosing with tungsten-iron, and tungsten-polymer shot in adult game-farm mallards. J. Wildl. Diseases 37: 451-458.

2001b. Haematological effects and metal residue concentrations following chronic dosing with tungsten-iron and tungsten-polymer shot in adult game-farm mallards. J. Wildl. Diseases 37: 459-467.

Munoz, M.C., Barbera, A., Dominguez, J., Fernandez-Alvarez, R., Gomis, R., and Guinovart, J.J. 2001. Effects of tungstate, a new potential antidiabetic agent, in Zucker diabetic fatty rats. Diabetes 50: 131-138.

National Toxicology Program. 2005. Nickel compounds and metallic nickel. In. Eleventh Report on Carcinogens. U.S. Dept. Health Human Services, Public Health Service. Atlanta, GA. Pp. 181-184.

Noer, H., Madsen, J., Hartmann, P. 2007. Reducing wounding of game by shotgun hunting: effects of a Danish action plan on pink-footed geese. J. Appl. Ecol. 44: 653-662.

Ogundipe, A., Greenberg, B., Braida, W., Christodoulatos, C., and Dermatas, D. 2006. Morphological characterization and spectroscopic studies of the corrosion behaviour of tungsten heavy alloys. Corrosion Sci. 48: 3281-3297.

Ogundipe, A.A., Braida, W.J., Koutsospyros, A., Christodoulatos, C., O’Connor, G., Larson, S. 2007. Letters to the editor. Sci. Total. Environ. In press.

Peuster, M., Fink, C., von Schankenburg, C. 2003a. Biocompatibility of corroding tungsten coils: in vitro assessment of degradation kinetics and cytotoxicity on human cells. Biomaterials 24: 4057-4061. 
Peuster, M., Fink, C., Wohlsein, P., Breugmann, M., Gunther, A., Kaese, V., Niemeyer, M., Haferkamp, K., von Schankenburg, C. 2003b. Degradation of tungsten coils implanted into the subclavian artery of New Zealand white rabbits is not associated with local or systemic toxicity. Biomaterials 24: 393-399.

Quin, B.F., Brooks, R.R. 1972a. The rapid determination of tungsten in soils, stream sediments, rocks and vegetation. Anal. Chim.Acta 58: 301-309.

Quin, B.F., Brooks, R.R. 1972b. Tungsten content of some plants from a mineralized area in New Zealand. N.Z. J. Sci. 15: 308-312.

Ringelman, J.K., Miller, M.W., Andelt, W.F. 1993. Effects of ingested tungsten-bismuthtin shot on captive mallards. J. Wildl. Manage. 57: 725-732.

Rubin, C.S., Holmes, A.K., Belson, M.G., Jones, R.L., Flanders, W.D., Kieszak, S.M., Osterloh, J., Luber, G.E., Blount, B.C., et al. 2007. Investigating childhood leukemia in Churchill County, Nevada. Environ. Health Perspectives 115: 151157.

Salnikow, K., Kasprzak, K. 2005. Ascorbate depletion: a critical step in nickel carcinogenesis? Environ. Health Perspectives 113: 577-584.

Schroeder, H.A. and Mitchener, M. 1975. Life-term studies in rats: effects of aluminum, barium, beryllium, and tungsten. J. Nutrition 105: 421-427.

Seiler, R.L., Stollenwerk, K.G., Garbarino, J.R. 2005. Factors controlling tungsten concentrations in ground water, Carson Desert, Nevada. Appl. Geochem. 20: 423441.

Senesi, N., Padovano, G., Brunetti, G. 1988. Scandium, titanium, tungsten and zirconium content in commercial inorganic fertilizers and their contribution to soil. Environment. Technol. Letters 9: 1011-1020.

Sheppard, P.R., Ridenour, G., Speakman, R.J., Witten, M.L. 2006. Elevated tungsten and cobalt in airborne particulates in Fallon, Nevada: possible implications for the childhood leukemia cluster. Appl. Geochem. 21: 152-165.

Sheppard, P.R., Speakman R.J., Ridenour, G., and Witten, M.L. 2007. Temporal variability of tungsten and cobalt in Fallon, Nevada. Env. Health Perspectives 115: 715-719.

Strigul, N., Koutsospyros, A., Arienti, P., Christodoulatos, C., Dermatas, C., and Braida, W. 2005. Effects of tungsten on environmental systems. Chemosphere 61: 248258. 
Sugio, T., Kuwano, H., Negishi, A., Maeda, T., Takeuchi, F., and Kamimura, K. 2001. Mechanism of growth inhibition by tungsten in Acidithiobacillus ferrooxidans. Biosci. Biotech. and Biochem. 65: 555-562.

Tajima, Y. 2003. The effects of tungstophosphate and tungstosilicate on various stress promoters transformed in Escherischia coli. J. Inorganic Biochem. 94: 155-160.

Taveccchia, G., Pradel, R., Lebreton, J.-D., Johnson, A.R., Mondain-Monval, J.-Y. 2001. The effect of lead exposure on survival of adult mallards in the Camargue, southern France. J. Appl. Ecol. 38: 1197-1207.

Thomas, V.G. Guitart, R., 2003. Evaluating non-toxic substitutes for lead shot and fishing weights; criteria and regulations. Environ. Policy Law 33: 150-154.

Thomas, V.G., Santore, R. C., McGill, I. 2007. Release of copper from sintered tungstenbronze shot under different $\mathrm{pH}$ conditions and its potential toxicity to aquatic organisms. Sci. Total Environ. 374: 71-79.

Uo, M., Watari, F., Yokoyama, A., Matsuno, H., Kawasaki, T. 2001. Tissue reaction around metal implants observed with X-ray scanning analytical microscopy. Biomaterials 22: 677-685.

USEPA (U.S. Environmental Protection Agency) 1995. A guide to the biosolids risk assessments for the EPA Part 503 Rule. EPA 832-B-93-005. U.S. Environ. Protect. Agency, Office of Wastewater Management. Washington, D.C.

USFWS (U.S. Fish and Wildlife Service), 1986. Use of lead shot for hunting migratory birds. Final supplemental environmental impact statement 1986. Office of Migratory Bird Management, Department of the Interior. U.S. Govt. Printing Office. Washington, D.C.

USFWS (U.S. Fish and Wildlife Service), 1997. Migratory bird hunting: revised test procedure for nontoxic shot approval procedure for shot and shot coatings. Fed. Register 62(320):63607-63615.

USFWS (U.S. Fish and Wildlife Service). 2006. Migratory Bird Hunting: Approval of Tungsten-Iron-Copper-Nickel, Iron-Tungsten-Nickel alloy, Tungsten-Bronze (Additional Formulation), and Tungsten-Tin-Iron Shot Types as Non-Toxic for Hunting Waterfowl and Coots: Availability of Environmental Assessments. Fed. Register 71(17): 4294-4297.

van der Voet, G.B., Todorov, T.I., Centeno, J.A., Jonas, W., Ives, J., Mullick, F.G. 2007. Metals and health: a clinical toxicological perspective on tungsten and review of the literature. Military Med. 172: 1002-1005. 
1 Table 1. Chemical composition of shot types containing tungsten approved as non-toxic for hunting waterfowl in the US and Canada. Table contents are based on data in USFWS (2006). Shot coatings of copper, nickel, tin, zinc, zinc chloride, and zinc-chrome are also approved for use on approved types of non-toxic shot. Not all of the shot types listed below may be sold widely in North America.

Tungsten-iron

Tungsten-iron-nickel

Tungsten-iron-tin

Tungsten-iron-copper-nickel

Tungsten-iron-tin-nickel

Tungsten-bronze ( 2 products)

Tungsten-tin-bismuth

Tungsten-matrix

Tungsten-polymer
Any proportion of $\mathrm{W}$ and $\geq 1 \% \mathrm{Fe}$

Any proportion of $\mathrm{W}, \geq 1 \% \mathrm{Fe}$, and up to $40 \% \mathrm{Ni}$

Any proportions of $\mathrm{W}$ and $\mathrm{Sn}$, and $\geq 1 \% \mathrm{Fe}$

$40-76 \% \mathrm{~W}, 10-37 \% \mathrm{Fe}, 9-16 \% \mathrm{Cu}, 5-7 \% \mathrm{Ni}$

$65 \% \mathrm{~W}, 10.4 \% \mathrm{Fe}, 21.8 \% \mathrm{Sn}, 2.8 \% \mathrm{Ni}$

$51.1 \% \mathrm{~W}, 44.4 \% \mathrm{Cu}, 3.9 \% \mathrm{Sn}, 0.6 \% \mathrm{Fe}$ $60 \% \mathrm{~W}, 35.1 \% \mathrm{Cu}, 3.9 \% \mathrm{Sn}, 1 \% \mathrm{Fe}$

Any proportions of $\mathrm{W}, \mathrm{Sn}$, and $\mathrm{Bi}$

$95.9 \% \mathrm{~W}, 4.1 \%$ polymer

$95.5 \% \mathrm{~W}, 4.5 \%$ Nylon 6 or 11 